\title{
A Presença e o Impacto de Periódicos Brasileiros da Área de Administração, Contabilidade e Turismo em Bases Científicas
}

\author{
Rodrigo Assunção Rosa e Marcello Romani-Dias
}

\section{RESUMO}

Rankings de periódicos elaborados por bases científicas têm influenciado pesquisadores, programas de Stricto Sensu e instituições que integram nossa academia. Diante do reduzido número de estudos de base empírica e quantitativa sobre esse tema, acessamos Web of Science (WoS), Scopus, Google Scholar, Scielo e Spell com a finalidade de respondermos a seguinte questão: Qual é a classificação dos periódicos brasileiros de Administração, Contabilidade e Turismo nas diferentes bases que calculam fator de impacto? Como resultados, notamos (i) ínfima presença e crescimento do impacto dos periódicos nas bases Scopus e Scielo, (ii) crescimento razoável na WoS, porém oriundo principalmente de autocitações, de citações nacionais de periódicos e de citações de autores brasileiros, (iii) alta correlação entre diferentes medidas de impacto, (iv) inexistência de diferença significante das médias de impacto entre alguns estratos Qualis em diferentes medidas e (v) variação considerável no impacto de um mesmo periódico em diferentes bases internacionais e nacionais.

Palavras-Chave: produção científica; bases científicas; publicação científica; periódicos científicos; fator de impacto de periódicos; internacionalização científica

The Presence and Impact of Brazilian Journals of Administration, Accounting and Tourism Area on Scientific Bases

\section{ABSTRACT}

Rankings of journals elaborated by scientific bases influence researchers, Stricto Sensu programs and institutions of our academy. Given the small number of empirical and quantitative studies on this subject, we have accessed Web of Science (WoS), Scopus, Google Scholar, Scielo and Spell in order to answer the following question: What is the classification of the Brazilian journals of Administration, Accounting and Tourism in the different bases that calculate impact factor? As a result, we noticed (i) the small presence and growth of the impact of the journals on the Scopus and Scielo bases, (ii) reasonable growth in WoS, but mainly from self-citations, national citations of periodicals and quotations from Brazilian authors, (iii) high correlation between different measures of impact, (iv) lack of significant difference in impact means between some Qualis stratum in different measures, and (v) considerable variation in the impact of the same journal report on different international and national bases.

Keywords: scientific production; scientific bases; scientific publishing; scientific journals; impact factor of journals; scientific internationalization

\section{Rodrigo Assunção} Rosa (iD),

Programa de Pós-Graduação em Administração de Empresas, Escola de Administração de Empresas de São Paulo, Brasil

Doutorando em Administração, Escola de Administração de Empresas de São Paulo, Brasil (EAESP-FGV)

rodrigo.assuncao.r@gmail.com

Marcello Romani-Dias (iD, Universidade Positivo; Escola Superior de Engenharia e Gestão (ESEG), Brasil Doutor em Administração, Escola de Administração de Empresas de São Paulo, Brasil (EAESP-FGV)

mromdias@hotmail.com 


\section{Introdução: O uso das Medidas de Impacto pela Comunidade Acadêmica}

Parte substancial dos periódicos brasileiros busca seguir padrões determinados pela comunidade acadêmica internacional (Saes, Mello, \& Sandes-Guimarães, 2017). Os rankings de artigos e periódicos expostos em bases científicas internacionais acabam por definir, para muitos, o que é um artigo de qualidade e o que é um periódico de expressão internacional (Blattmann \& Santos, 2014; Harzing \& Alakangas, 2016; Machado-da-Silva, Guarido Filho, Rossoni, \& Graeff, 2008). Como exemplo, a última avaliação do Qualis-Periódicos tomou como critério os rankings de algumas bases científicas para avaliar a qualidade de periódicos no quadriênio 2013-2016 (Capes, 2017). Os programas Stricto Sensu no Brasil vinculam a habilidade de publicação de seus professores pesquisadores e de seus alunos de Mestrado, Doutorado e Pós-Doutorado aos critérios adotados pelas bases, até porque é também a partir desses critérios que os próprios programas são avaliados pela Coordenação de Aperfeiçoamento de Pessoal de Nível Superior (Capes). Consequentemente, os pesquisadores constantemente consultam bases científicas e analisam o impacto de periódicos no esforço por escolher em quais pretendem lograr êxito em suas publicações (Ferreira, 2015).

Existem pelo menos 140 indexadores científicos em que os periódicos brasileiros de Administração, Contabilidade e Turismo estão inseridos (Rosa \& Romani-Dias, 2017). Dentre estes indexadores, há bases que não somente catalogam e disponibilizam conteúdos de artigos e periódicos, mas que também realizam o cálculo por meio das medidas de impacto dos periódicos, sempre com o intuito de divulgar a relevância e legitimidade de cada periódico em sua respectiva área acadêmica, como é o caso das bases Web of Science, Scopus, Google Scholar, Scielo e Spell, que estão entre as indexadores mais utilizados pela comunidade científica mundial e nacional (Diniz, 2017; Harzing \& Alakangas, 2016; Trzesniak, 2016).

Diante deste grande e importante universo de indexadores e medidas, autores como Diniz (2017), Farias (2017), Wood Jr e Costa (2015) têm investigado a influência das bases científicas e das diferentes medidas de impacto em nossa academia. Alguns autores, como é o caso de Alcadipani (2017), Trzesniak (2016) e Rossoni (2018b), adotam uma perspectiva crítica e vão além, questionando a relevância dos critérios e das próprias medidas de fator de impacto adotados pela comunidade acadêmica brasileira. Estes trabalhos evidenciam que as bases calculam o impacto dos periódicos a partir do número de publicações e citações recebidas de seus artigos, porém, por meio de diferentes indicadores, sendo oportuno indagar a respeito da pertinência de se utilizar determinadas medidas de impacto em detrimento de outras no campo de Administração, Contabilidade e Turismo (Capes, 2017). Além disso, cada base compõe um conjunto diferente de periódicos para a composição de seus fatores de impacto, o que pode levar a incongruências entre os diferentes rankings de periódicos, alimentados pelas medidas de impacto calculadas (Trzesniak, 2016). 
Apesar destas fundamentais descobertas e contribuições das pesquisas mencionadas, não identificamos na literatura estudos que partam de dados empíricos para explorar e testar as relações entre os periódicos acadêmicos e as bases científicas de que fazem parte, haja vista que a maioria dos autores têm preferido uma abordagem teórica reflexiva para endereçarem suas questões de pesquisa. Para atendermos a essa lacuna, acessamos as bases Web of Science, Scopus, Google Scholar, Scielo e Spell com a finalidade de respondermos a seguinte questão de pesquisa: Qual é a classificação dos periódicos brasileiros de Administração, Contabilidade e Turismo nas diferentes bases científicas que calculam fator de impacto?

Ao respondermos a questão proposta pretendemos trazer contribuições para os periódicos e, ao incitarmos a discussão - fundamentada nos dados sobre o posicionamento nacional e internacional de nossos periódicos frente às bases científicas para a Capes, propomos medidas complementares para a atual avaliação Qualis-periódicos e para os pesquisadores e instituições de ensino. Dessa forma, discorremos sobre características de periódicos nacionais que podem ser estratégicas para as publicações dos pesquisadores e para os programas de que fazem parte.

Organizamos nosso artigo em seis seções, incluindo esta Introdução. Na segunda seção, de revisão de literatura, tratamos das bases científicas e de sua relevância para os periódicos acadêmicos, o que inclui a apresentação das atuais bases utilizadas pela Capes em seu processo de avaliação de periódicos. A seção de número três traz os métodos que adotamos neste estudo, e trata especialmente dos instrumentos de coleta de dados utilizados, dos mecanismos que deram maior confiabilidade para o estudo e das estratégias de análise de dados que desenvolvemos. $\mathrm{Na}$ seção de número quatro iniciamos nossa análise de resultados sobre as diferentes medidas de impacto de nossos periódicos nas bases científicas e na seção de número cinco tratamos das implicações e recomendações para a área de Administração, Contabilidade e Turismo. Na seção de Considerações Finais, a sexta e última do artigo, retomamos o objetivo e as contribuições de nosso estudo, tratamos de suas limitações e apresentamos oportunidades de pesquisas futuras dentro desta grande temática da Publicação Científica.

\section{Bases Científicas: Relevância, Medidas de Impacto e uso pela Capes}

Nas últimas décadas, a utilização de medidas de impacto tem sido prática comum entre acadêmicos de diferentes nacionalidades e áreas do conhecimento na avaliação de periódicos científicos, pesquisadores e instituições, e até mesmo na mensuração do grau de inovação dos países (Machado-da-Silva et al., 2008; Mingers, O'hanley, \& Okunola, 2017; Mongeon \& Paul-Hus, 2016). As bases de dados científicas são as fontes pelas quais as diferentes métricas são geradas e compartilhadas, e compõem um conjunto significativo de artigos e periódicos indexados, sendo possível que os pesquisadores realizem a procura e o acesso a informações de relevância científica a partir delas (Harzing \& Alakangas, 2016). Com o 
advento da internet e do desenvolvimento e avanço das tecnologias da informação e comunicação, diferentes empresas e instituições passaram a realizar o serviço de indexação de periódicos e artigos científicos, por meio do qual facilitaram a procura, acesso e disseminação de um conjunto considerável de periódicos, em que antes o acesso era possível apenas de forma impressa (Solomon, 2014).

Atualmente, as bases científicas mais reconhecidas no meio acadêmico mundial, e que calculam medidas de impacto, são a Web of Science, gerida pela Clarivate Analytics (Falagas, Pitsouni, Malietzis, \& Pappas, 2008; Harzing \& Alakangas, 2016; Mongeon \& Paul-Hus, 2016; Trzesniak, 2016) a Scopus, de propriedade da editora Elsevier (Falagas et al., 2008; Harzing \& Alakangas, 2016; Mongeon \& Paul-Hus, 2016; Trzesniak, 2016), e o Google Scholar, da empresa Google LLC (Harzing \& Alakangas, 2016; Moed, Bar-llan, \& Halevi, 2016; Mongeon \& Paul-Hus, 2016). Em nível Ibero-americano temos a base Scielo (Aguado-López, Garduño-Oropeza, Rogel-Salazar, \& Zúñiga-Roca, 2012; Collazo-Reyes, 2014; Diniz, 2017; Trzesniak, 2016), que teve origem na parceria entre FAPESP, BIREME (Centro Latino-Americano e do Caribe de Informação em Ciências da Saúde) e também com apoio do CNPq (Diniz, 2017), e em nível nacional, mais especificamente na área de Administração, Contabilidade e Turismo, a base Spell (Simioni, Dallacorte, \& Jacoski, 2016; Diniz, 2017; Trzesniak, 2016), gerida pela ANPAD e IBEPES, que passou a ser considerada um importante meio de indexação dos periódicos brasileiros da área, realizando também o cálculo do fator de impacto dos periódicos (Capes, 2017; Rossoni, 2018a; Saes, Mello \& Sandes-Guimarães, 2017).

Essas bases em conjunto são responsáveis por diferentes métricas que calculam o impacto de um grupo de periódicos indexados. A quantidade de citações recebida de um periódico por outros periódicos por meio das publicações de artigos científicos e o número de artigos publicados por este são, em grande parte, os principais indicadores que conferem legitimidade a um grupo de periódicos indexados em bases de dados (Harzing \& Alakangas, 2016). A Tabela 1 mostra as principais bases presentes na literatura, bem como a descrição e interpretação das medidas adotadas por elas:

Estas cinco bases, portanto, fazem parte de discussões acadêmicas frequentes e muitas vezes são utilizadas como critério para definir a qualidade de periódicos científicos (Blattmann \& Santos, 2014). No Brasil, por exemplo, a Capes é a entidade governamental responsável pela avaliação dos periódicos brasileiros quanto à qualidade de suas publicações (Capes, 2017), e utiliza as medidas calculadas por essas bases para esta avaliação, com exceção do h5-index do Google Scholar, do SJR da Scopus e dos índices h-Spell e Spell 2 anos (apenas o Spell 5 anos é considerado pelo Qualis-periódicos, denominação da avaliação feita pela Capes). A título de ilustração, o índice Spell 5 anos é um dos critérios utilizados para classificar os periódicos nos estratos B3, B2 e B1; o Scielo Fl é um dos critérios utilizados para classificar os periódicos nos estratos B2 e B1, e os índices JCR e H-Scopus são considerados para classificar os periódicos nos estratos B1, A2 e A1, sendo que os periódicos presentes nestes últimos estratos são considerados os mais elevados no que se refere a sua qualidade, de acordo com o Qualis-periódicos (Capes, 2017). 
Tabela 1. As Bases Científicas e suas Principais Medidas de Impacto

\begin{tabular}{|c|c|c|c|}
\hline Base & Medida & Descrição & Interpretação do indicador \\
\hline Web of Science & JCR & $\begin{array}{l}\text { Quociente entre } 0 \text { número de citações } \\
\text { recebidas e quantidade de artigos publicados } \\
\text { pelo periódico nos últimos dois anos }\end{array}$ & $\begin{array}{l}\text { JCR } 2016=0.5 \text {; Nos anos de } 2014 \text { e } 2015 \\
0 \text { periódico recebeu } 25 \text { citações e publicou } \\
50 \text { artigos }\end{array}$ \\
\hline Scopus & H-Scopus & $\begin{array}{l}\text { O periódico possuí H artigos que receberam H } \\
\text { ou mais citações na base }\end{array}$ & $\begin{array}{l}\text { H-Scopus = 16; } 16 \text { artigos do periódico foram } \\
\text { citados } 16 \text { vezes ou mais na base Scopus }\end{array}$ \\
\hline Scopus & SJR & $\begin{array}{l}0 \text { cálculo é baseado em uma fórmula complexa } \\
\text { que leva em consideração diversas variáveis, } \\
\text { tais como citações, quantidades de referências, } \\
\text { número de periódicos e número de artigos }\end{array}$ & Ver Scimago ${ }^{1}$ (2018) \\
\hline Scielo & Scielo FI 2 anos & $\begin{array}{l}\text { Quociente entre } 0 \text { número de citações } \\
\text { recebidas e quantidade de artigos publicados } \\
\text { pelo periódico nos últimos dois anos }\end{array}$ & $\begin{array}{l}\text { Scielo } \mathrm{Fl} 2016=1.5 \text {; Nos anos de } 2014 \text { e } 2015 \\
0 \text { periódico recebeu } 75 \text { citações e publicou } \\
50 \text { artigos }\end{array}$ \\
\hline Google Scholar & h5-index & $\begin{array}{l}\text { H artigos publicados de } 2012 \text { a } 2016 \text { que } \\
\text { foram citados no mínimo H vezes cada }\end{array}$ & $\begin{array}{l}\text { h5-index }=10 ; 10 \text { artigos publicados de } 2012 \\
\text { a } 2016 \text { foram citados no mínimo } 10 \text { vezes cada }\end{array}$ \\
\hline Spell & h-Spell & $\begin{array}{l}\mathrm{O} \text { periódico possuí } \mathrm{H} \text { artigos que receberam } \mathrm{H} \\
\text { ou mais citações na base }\end{array}$ & $\begin{array}{l}\text { h-Spell }=10 ; 10 \text { artigos do periódico foram } \\
\text { citados } 10 \text { vezes ou mais na base Spell }\end{array}$ \\
\hline Spell & Spell 2 anos & $\begin{array}{l}\text { Quociente entre o número de citações } \\
\text { recebidas e quantidade de artigos publicados } \\
\text { pelo periódico nos últimos dois anos }\end{array}$ & $\begin{array}{l}\text { A interpretação é a mesma das medidas JCR e } \\
\text { Scielo FI } 2 \text { anos }\end{array}$ \\
\hline Spell & Spell 5 anos & $\begin{array}{l}\text { Quociente entre o número de citações } \\
\text { recebidas e quantidade de artigos publicados } \\
\text { pelo periódico nos últimos cinco anos }\end{array}$ & $\begin{array}{l}\text { A interpretação é a mesma das medidas JCR e } \\
\text { Scielo FI, no entanto considera os últimos cinco } \\
\text { anos }\end{array}$ \\
\hline
\end{tabular}

Fonte. Elaborado pelos autores a partir das bases de dados.

Nota. Parte dessas medidas são utilizadas pela Capes na classificação de periódicos, que são classificadas em um dos estratos B5, B4,B3, B2, B1, A2 e A1. Tais estratos estão em ordem crescente de qualidade, ou seja, periódicos do estrato A são considerados os de maior qualidade pelo Qualis-periódicos.

Pela relevância deste tema para nossa academia, diversos pesquisadores do campo de Administração, Contabilidade e Turismo têm refletido a respeito da importância das bases de dados científicas, das medidas de impacto e da internacionalização de nossos periódicos por meio destas bases (Alcadipani, 2017; Diniz, 2017; Farias; 2017; Ferreira, 2015; Saes, Mello, \& Sandes-Guimarães, 2017; Trzesniak, 2016; Wood Jr \& Costa, 2015). Todavia, o foco destas pesquisas tem sido teórico, o que nos motivou a trazer dados empíricos relevantes para a discussão e implicações sobre os periódicos científicos nacionais de nosso campo, conforme destacaremos na seção de método e análise de dados.

\section{Método e Análise de Dados}

Para responder à questão de pesquisa adotamos a abordagem quantitativa de investigação (Creswell, 2007; Mugenda, 1999; Neuman, 2014), em que se busca, a partir de uma amostra ou população, realizar

1 Description of Scimago Journal Rank Indicador. Recuperado em 12 fevereiro, 2019, de: https://www. scimagojr.com/SCImagoJournalRank.pdf 
inferências sobre as características de determinados objetos de estudo ou a respeito das relações entre variáveis de determinado fenômeno pesquisado. Em nosso artigo, buscamos inferir sobre a classificação dos periódicos brasileiros de Administração, Contabilidade e Turismo nas diferentes bases científicas que calculam medidas de impacto, sendo este o fenômeno investigado. Tratamos, portanto, da relação estatística entre os periódicos e as bases científicas de que fazem parte.

Como consequência dessa escolha, nosso posicionamento epistemológico neste artigo é objetivista, com base na classificação de Morgan e Smircich (1980). Isto ocorre porque ao analisarmos o cenário dos periódicos brasileiros estamos, na verdade, tratando de uma estrutura concreta (e atual) que afeta nossa academia (nas áreas de Administração, Contabilidade e Turismo) como um todo, afastando-se, portanto, de uma abordagem subjetivista, centrada na análise e interpretação do indivíduo a partir de uma construção social (Burrell \& Morgan, 1979; Cunliffe, 2011; Morgan \& Smircich, 1980).

Os procedimentos metodológicos que adotamos podem ser divididos em cinco etapas de coleta e análise de dados, realizadas entre os meses de agosto de 2017 e junho de 2018. Na primeira etapa tivemos o intuito de identificarmos uma amostra muito próxima à população de periódicos nacionais da área de Administração, Contabilidade e Turismo, e para chegarmos a essa amostra analisamos a lista de periódicos presentes no Qualis-periódicos da Capes (2017) do Quadriênio 2013-2016, classificados entre os estratos A2 e B5 (tendo em vista que não existem periódicos brasileiros de nossa área no estrato A1). O documento do Qualis-periódicos foi utilizado para fins de levantamento, pois é o mais completo em termos dos periódicos nacionais vigentes, visto que é gerado a partir da coleta das publicações de todos os professores pesquisadores vinculados aos programas de Pós-graduação Scricto Sensu do país entre os anos de 2013 e 2016. Além disso, foi a escolha que trouxe maior confiabilidade ao estudo, pois com base na acurácia da amostra selecionada, tornou-se possível realizarmos inferências sobre a população, seguindo os preceitos de Anderson, Sweeney e Williams (2007).

Em uma segunda etapa de pesquisa, também como forma de trazermos maior confiabilidade ao estudo, adotamos critérios de permanência ou exclusão dos periódicos identificados inicialmente na lista do Qualis-periódicos, ao analisarmos documentos existentes nos websites de tais periódicos. O critério de permanência correspondeu à manutenção de periódicos nacionais alinhados em seus focos e escopos aos temas e às áreas correlatas ao campo de Administração, Contabilidade e Turismo. Como critérios de exclusão, eliminamos os periódicos que não possuíam acesso livre, periódicos não oriundos do Brasil, periódicos que estavam replicados no documento da Capes, periódicos com volumes exclusivamente impressos, periódicos de natureza interdisciplinar e multidisciplinar, e que não tenham como central as temáticas do campo, e também periódicos de outros campos do conhecimento, tais como Sociologia, Antropologia, Psicologia, Educação e Enfermagem. Após esse critério de tratamento de dados, chegamos a uma amostra final de 304 periódicos brasileiros classificados entre os estratos A2 e B5 (Sci\&Org, 2018). 
Com este número final de periódicos iniciamos a terceira etapa da pesquisa, que consistiu em (i) verificarmos nos websites dos periódicos quais estavam indexados nas bases científicas que possuem indicadores de impacto - Web of Science, Scopus, Scielo, Spell e Google Scholar - e (ii) confrontarmos a presença (ou ausência) dos referidos periódicos, realizando buscas diretamente nas bases científicas mencionadas, com a finalidade de triangularmos nossos dados e, consequentemente, de trazermos maior confiabilidade ao estudo. Após esta terceira etapa chegamos à distribuição exposta na Tabela 2:

Tabela 2. Distribuição dos Periódicos Investigados nos Estratos Capes e nas Bases Científicas

\begin{tabular}{ccccccccc}
\hline Estrato & & A2 & B1 & B2 & B3 & B4 & B5 & Total \\
\hline \multirow{2}{*}{$\begin{array}{c}\text { Periódicos } \\
\text { Identificados }\end{array}$} & Total & 17 & 30 & 42 & 70 & 107 & 38 & 304 \\
\cline { 2 - 9 } & $\%$ & $5,59 \%$ & $9,87 \%$ & $13,82 \%$ & $23,03 \%$ & $35,20 \%$ & $12,50 \%$ & $100,00 \%$ \\
\hline \multirow{2}{*}{ Web of Science } & Total & 2 & 1 & 0 & 0 & 0 & 0 & 3 \\
\cline { 2 - 9 } & $\%$ & $11,76 \%$ & $3,33 \%$ & $0,00 \%$ & $0,00 \%$ & $0,00 \%$ & $0,00 \%$ & $0,99 \%$ \\
\hline \multirow{2}{*}{ Scopus } & Total & 6 & 5 & 2 & 0 & 0 & 0 & 13 \\
\cline { 2 - 9 } & $\%$ & $35,29 \%$ & $16,67 \%$ & $4,76 \%$ & $0,00 \%$ & $0,00 \%$ & $0,00 \%$ & $4,28 \%$ \\
\hline \multirow{2}{*}{ Scielo } & Total & 12 & 5 & 1 & 0 & 0 & 0 & 18 \\
\cline { 2 - 9 } & $\%$ & $70,59 \%$ & $16,67 \%$ & $2,38 \%$ & $0,00 \%$ & $0,00 \%$ & $0,00 \%$ & $5,92 \%$ \\
\hline \multirow{2}{*}{ Spell } & Total & 16 & 23 & 37 & 29 & 3 & 1 & 109 \\
\cline { 2 - 8 } & $\%$ & $94,12 \%$ & $76,67 \%$ & $88,10 \%$ & $41,43 \%$ & $2,80 \%$ & $2,63 \%$ & $35,86 \%$ \\
\hline \multirow{2}{*}{ Google Scholar } & Total & 16 & 26 & 37 & 30 & 20 & 5 & 134 \\
\cline { 2 - 8 } & $\%$ & $94,12 \%$ & $86,67 \%$ & $88,10 \%$ & $42,86 \%$ & $18,69 \%$ & $13,16 \%$ & $44,08 \%$ \\
\hline
\end{tabular}

Fonte: Elaborado pelos autores.

$\mathrm{Na}$ quarta etapa de pesquisa coletamos as principais informações dos impactos dos periódicos em listas documentadas nas bases, quais sejam: (a) Web of Science: JCR entre 2013 e 2016 e as citações recebidas de periódicos indexados na mesma base; (b) Scopus: H-Scopus e SJR dos últimos quatro anos; (c) Scielo: Scielo Fator de Impacto 2 anos; (d) Spell: h-Spell, Spell 2 anos e Spell 5 anos, sem autocitação; (e) Google Scholar: h5-index (calculado com base nas citações recebidas entre 2012 e 2016). Ademais, excluímos da análise os periódicos de estrato B5 para as bases Google Scholar e Spell, e B4 para Spell, por conterem uma amostra muito pequena em relação aos demais estratos.

Na quinta e última etapa de pesquisa realizamos a análise de dados a partir da tabulação dos dados coletados no software Excel e por meio da utilização do software Minitab 18. Dado que as bases possuem amostras de periódicos nacionais distintas, optamos pela utilização de técnicas descritivas, tais como frequência, média e desvio padrão. Também optamos pela utilização de correlação de Spearman nas bases com amostras consideráveis (Spell e Google Scholar), além da técnica de análise de variância (ANOVA) para verificarmos a diferença estatística entre as médias de impacto dos grupos, com a aplicação do teste de Tukey, tendo em vista que a comparação realizada deu-se em mais de dois grupos, seguindo os preceitos de Hair, Black, Babin, Anderson e Tatham (2009), ou seja, procedemos a comparação da média dos impactos entre os estratos A2 e B4 da classificação Qualis-Periódicos. 


\section{Análise de Resultados: O Impacto de Periódicos Brasileiros em Diferentes Bases}

Identificamos que apenas três periódicos nacionais da área estão indexados na base Web of Science: Revista de Administração de Empresas (RAE), Revista Brasileira de Gestão de Negócios (RBGN) e Custos e Agronegócio Online (C\&A). A análise do fator de impacto JCR revela o aumento dos fatores de impacto da RAE e RBGN no quadriênio 2013-2016, que cresceram, respectivamente, $220 \%$ (de 0,185 para 0,408) e 364\% (de 0,042 para 0,153). O periódico Custos e Agronegócio Online teve queda considerável entre os anos de 2013 e 2015 (de 0,175 para 0,028), mas houve recuperação em 2016 para 0,162, ficando próximo ao impacto do periódico RBGN, conforme Figura 1:

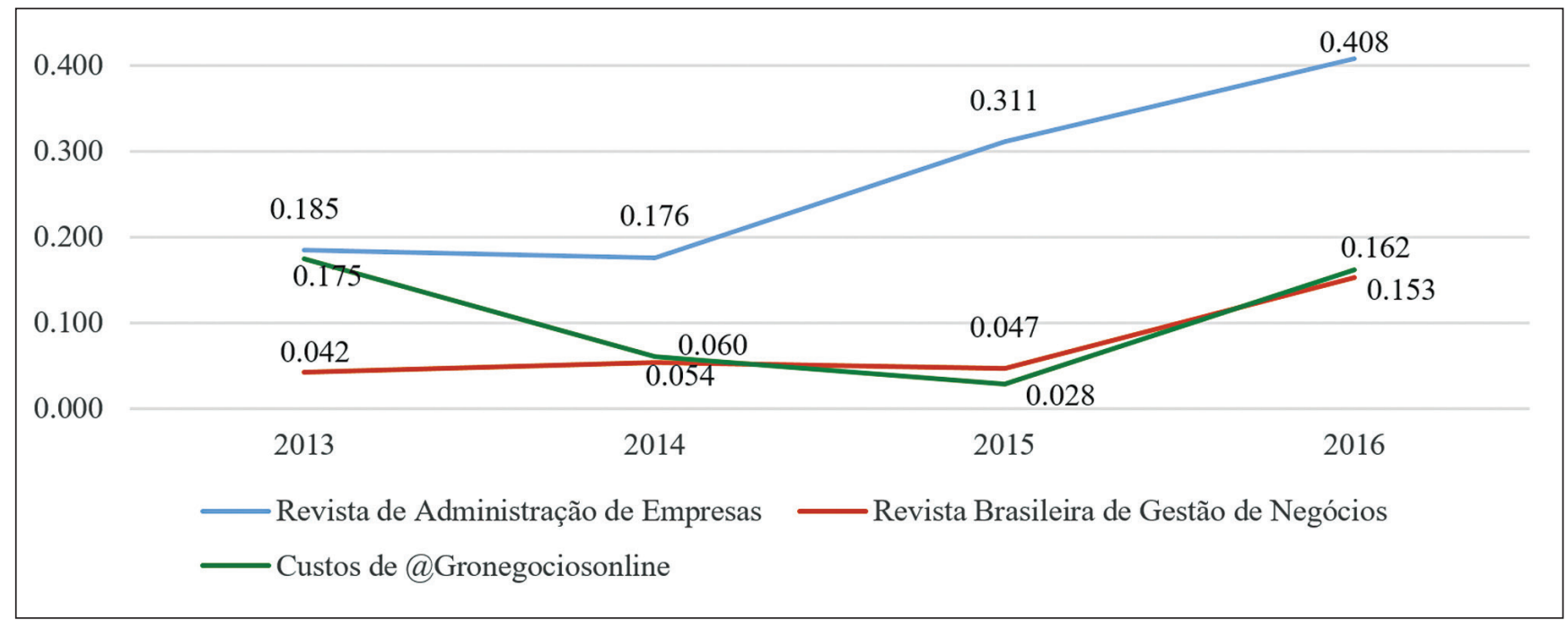

Figura 1. Evolução do Impacto dos Periódicos Brasileiros da área na Web of Science entre 2013 e 2016 Fonte: Elaborado pelos autores.

Embora o panorama positivo em termos de crescimento do impacto entre 2015 e 2016, algumas questões revelam-se preocupantes em relação ao cenário dos periódicos diante da tentativa de internacionalização e aumento do impacto. Primeiro, o ranking JCR da área de Business e Management conta com 264 periódicos, sendo que nossos três periódicos indexados estão entre as últimas quinze posições do ranking: RAE em 249 Custos e Agronegócio Online em $261^{\circ}$ e RBGN em 262․ Segundo, ao verificar as citações recebidas por periódicos indexados na Web of Science, notamos a elevada quantidade de autocitação: 96,8\% no periódico Custos e Agronegócio, 46,1\% na RAE e 40\% no periódico RBGN. Terceiro, nenhum periódico nacional cita a RBGN e Custos e Agronegócio e a RAE é citada por alguns periódicos nacionais, mas as citações de periódicos brasileiros correspondem a 83,1\% do total de citações recebidas desta revista. A RBGN tem uma melhor proporção, 60\% de citação de periódicos internacionais, porém possuí apenas 15 citações no total. A Tabela 3 demonstra os principais periódicos que citaram as três revistas: 
Tabela 3. Origens das Citações de Periódicos Nacionais na Web of Science

\begin{tabular}{|c|c|c|c|c|c|c|c|}
\hline Periódicos na Web of Science & JCR2016 & RAE & Freq. & RBGN & Freq. & $\begin{array}{l}\text { Custos e } \\
\text { Agro }\end{array}$ & Freq. \\
\hline \multicolumn{8}{|c|}{ Periódicos Brasileiros } \\
\hline $\begin{array}{c}\text { Revista de Administração de } \\
\text { Empresas }\end{array}$ & 0.408 & 30 & $46,15 \%$ & 0 & $0,00 \%$ & 0 & $0,00 \%$ \\
\hline $\begin{array}{l}\text { Revista Brasileira de Gestão e } \\
\text { Negócios }\end{array}$ & 0.153 & 10 & $15,38 \%$ & 6 & $40,00 \%$ & 0 & $0,00 \%$ \\
\hline Custos e Agronegócio Online & 0.162 & 4 & $6,15 \%$ & 0 & $0,00 \%$ & 60 & $96,77 \%$ \\
\hline Cadernos de Saúde Pública* & 1.133 & 4 & $6,15 \%$ & 0 & $0,00 \%$ & 0 & $0,00 \%$ \\
\hline Ciência \& Saúde Coletiva* & 0.78 & 2 & $3,08 \%$ & 0 & $0,00 \%$ & 0 & $0,00 \%$ \\
\hline Revista Dados ${ }^{*}$ & 0.292 & 2 & $3,08 \%$ & 0 & $0,00 \%$ & 0 & $0,00 \%$ \\
\hline Informação \& Sociedade* & 0.086 & 2 & $3,08 \%$ & 0 & $0,00 \%$ & 0 & $0,00 \%$ \\
\hline \multicolumn{8}{|c|}{ Periódicos Internacionais } \\
\hline Journal of Business Research & 3.354 & 3 & $4,62 \%$ & 0 & $0,00 \%$ & 0 & $0,00 \%$ \\
\hline European Management Review & 1.333 & 2 & $3,08 \%$ & 0 & $0,00 \%$ & 0 & $0,00 \%$ \\
\hline Information and Organization & 2.083 & 2 & $3,08 \%$ & 0 & $0,00 \%$ & 0 & $0,00 \%$ \\
\hline Journal of Destination Mark. \& Man. & 1.556 & 2 & $3,08 \%$ & 0 & $0,00 \%$ & 0 & $0,00 \%$ \\
\hline Journal of Knowledge Management & 2.053 & 2 & $3,08 \%$ & 0 & $0,00 \%$ & 0 & $0,00 \%$ \\
\hline Revista Latinoam. de Administracion & 0.237 & 0 & $0,00 \%$ & 2 & $13,33 \%$ & 0 & $0,00 \%$ \\
\hline British Accounting Review & 2.135 & 0 & $0,00 \%$ & 1 & $6,67 \%$ & 0 & $0,00 \%$ \\
\hline Business Research Quarterly & 1.325 & 0 & $0,00 \%$ & 1 & $6,67 \%$ & 0 & $0,00 \%$ \\
\hline Business Ethics-A European Review & 1.906 & 0 & $0,00 \%$ & 1 & $6,67 \%$ & 0 & $0,00 \%$ \\
\hline Croatian Journal of Education & 0.126 & 0 & $0,00 \%$ & 1 & $6,67 \%$ & 0 & $0,00 \%$ \\
\hline Family Business Review & 4.229 & 0 & $0,00 \%$ & 1 & $6,67 \%$ & 0 & $0,00 \%$ \\
\hline $\begin{array}{l}\text { Int. Journal of Information } \\
\text { Management }\end{array}$ & 3.872 & 0 & $0,00 \%$ & 1 & $6,67 \%$ & 0 & $0,00 \%$ \\
\hline Journal of Family Business Strategy & 2.375 & 0 & $0,00 \%$ & 1 & $6,67 \%$ & 0 & $0,00 \%$ \\
\hline Land Use Policy & 3.089 & 0 & $0,00 \%$ & 0 & $0,00 \%$ & 1 & $1,61 \%$ \\
\hline Inter.Journal for Equity in Health & 1.738 & 0 & $0,00 \%$ & 0 & $0,00 \%$ & 1 & $1,61 \%$ \\
\hline Total & & 65 & $100,00 \%$ & 15 & $100,00 \%$ & 62 & $100,00 \%$ \\
\hline
\end{tabular}

Fonte: Elaborado pelos autores.

Nota. *revistas que não possuem foco e escopo na área. 
A base Scopus, que calcula o índice SJR, possuí 13 periódicos da área indexados, que variam entre os estratos A2 e B2 do Qualis. Nos últimos quatro anos, em geral, o crescimento do fator de impacto SJR foi baixo, dado que houve em média aumento de apenas 0,026 entre 2013 e 2014, queda de 0,009 entre 2014 e 2015 e aumento de 0,033 entre 2015 e 2016. Portanto, a média geral de impacto dos periódicos da área em 2016 cresceu pouco em comparação a 2013, demonstrando um cenário de irrisório crescimento na base Scopus. Cinco dos 13 periódicos tiveram seu melhor impacto no ano de 2014, cinco em 2016, dois em 2015 e um em 2013. O periódico Pesquisa Operacional é o único que atingiu um impacto acima de 0,500, chegando a 0,586 em 2016, sendo o periódico nacional da área de maior impacto na base. De forma geral, os periódicos estão em uma melhor posição no ranking da Scopus do que no da Web of Science, porém estão ainda muito distantes de atingir posições que os coloquem entre os periódicos intermediários da área. Na área de Business, Management e Accounting, dos 1394 periódicos indexados, os nossos se encontram ainda distantes dos 200 primeiros, que possuem um fator de impacto SJR mínimo de 1,045.

Das bases até aqui mencionadas na análise dos resultados, a Scielo é a que tem o maior número de periódicos nacionais da área indexados: são 18 periódicos que estão entre os estratos A2 e B2. A análise da média geral revela um cenário ainda mais preocupante que o da base Scopus: houve um pequeno aumento entre 2013 e $2014(0,017)$ e duas quedas, uma no ano de 2015 e outra em 2016. Com isso, o aumento do impacto médio dos periódicos da base é de apenas 11,34\%, tomando como referência os anos de 2013 e 2016, o que demonstra, em média, o insignificante crescimento dos periódicos na base. Seis periódicos tiveram seu maior impacto no ano de 2015, cinco em 2016 e quatro em 2013, sendo que quatro periódicos do estrato A2 tiveram impacto zero na base em 2016. A Revista de Administração Pública (RAP) é o periódico que teve maior impacto no ano de $2016(0,306)$, cerca do dobro em relação a 2015. Já a Revista de Administração de Empresas (RAE) é o periódico que teve maior impacto em relação a todos os anos, tendo 0,310 em 2015. A maior média de impacto da base foi em 2014, com 0,114 . Os resultados de impacto das bases Scopus e Scielo podem ser encontrados na Tabela 4: 
Tabela 4. 0 Fator de Impacto de Periódicos Nacionais na Scopus e Scielo

\begin{tabular}{|c|c|c|c|c|c|c|}
\hline \multicolumn{7}{|c|}{ Fator de Impacto Scopus - SJR } \\
\hline Estrato & $\begin{array}{c}\mathrm{H}- \\
\text { Scopus }\end{array}$ & Periódicos & 2013 & 2014 & 2015 & 2016 \\
\hline $\mathrm{A} 2$ & 13 & Pesquisa Operacional & 0,272 & 0,293 & 0,266 & $0,586^{*}$ \\
\hline A2 & 11 & Revista de Administração Pública & 0,202 & 0,213 & 0,216 & $0,236^{\star}$ \\
\hline B1 & 3 & Custos e @Gronegociosonline & 0,190 & 0,191 & $0,203^{*}$ & 0,201 \\
\hline B2 & 10 & Produção (Production) & 0,191 & $0,277^{\star}$ & 0,182 & 0,197 \\
\hline B1 & 11 & Gestão \& Produção & 0,156 & $0,206^{*}$ & 0,189 & 0,191 \\
\hline $\mathrm{A} 2$ & 9 & Brazilian Administration Review & 0,164 & 0,175 & $0,198^{\star}$ & 0,182 \\
\hline A2 & 5 & Revista Brasileira de Gestão e Negócios & 0,129 & $0,194^{*}$ & 0,150 & 0,181 \\
\hline A2 & 7 & Revista de Administração de Empresas & 0,203 & 0,201 & $0,206^{\star}$ & 0,155 \\
\hline B1 & 1 & Revista de Gestão Social e Ambiental & 0,000 & 0,101 & 0,142 & $0,145^{\star}$ \\
\hline B2 & 5 & RAMA: Revista em Agronegócio e Meio Ambiente & $0,143^{*}$ & 0,117 & 0,125 & 0,127 \\
\hline B1 & 3 & Revista Brasileira de Gestão e Desenv. Regional & 0,123 & $0,134^{*}$ & 0,107 & 0,113 \\
\hline A2 & 1 & Revista Contabilidade e Finanças & 0,000 & 0,000 & 0,000 & $0,111^{*}$ \\
\hline B1 & 1 & Revista Brasileira de Gestão Urbana & 0,000 & 0,000 & 0,000 & 0,000 \\
\hline & & Média SJR & 0,136 & 0,162 & 0,153 & $0,186^{\star}$ \\
\hline
\end{tabular}

Fator de Impacto Scielo - 2 anos

\begin{tabular}{|c|c|c|c|c|c|}
\hline A2 & Revista de Administração Pública & 0,114 & 0,173 & 0,149 & $0,306^{*}$ \\
\hline A2 & Revista de Administração de Empresas & 0,304 & 0,280 & $0,310^{\star}$ & 0,283 \\
\hline A2 & Revista de Administração Contemporânea & 0,172 & 0,214 & $0,263^{*}$ & 0,216 \\
\hline A2 & Brazilian Administration Review & 0,105 & 0,105 & 0,146 & $0,196^{*}$ \\
\hline A2 & Revista de Administração da Universidade de São Paulo & 0,164 & 0,114 & 0,123 & $0,167^{*}$ \\
\hline A2 & Pesquisa Operacional & 0,113 & $0,207^{*}$ & 0,138 & 0,161 \\
\hline A2 & Cadernos EBAPE.BR & 0,195 & 0,202 & $0,295^{*}$ & 0,138 \\
\hline B1 & Read. Revista Eletrônica de Administração & 0,083 & 0,117 & 0,067 & $0,117^{*}$ \\
\hline A2 & Revista Contabilidade \& Finanças & 0,057 & 0,028 & 0,000 & $0,104^{*}$ \\
\hline B1 & Revista Brasileira de Gestão Urbana & 0,000 & 0,100 & $0,159^{*}$ & 0,078 \\
\hline B2 & Produção (Production) & 0,172 & $0,176^{*}$ & 0,101 & 0,062 \\
\hline B1 & $\begin{array}{c}\text { Journal of Information Systems and Technology } \\
\text { Management }\end{array}$ & 0,000 & 0,034 & $0,077^{\star}$ & 0,062 \\
\hline B1 & Revista de Administração Mackenzie & 0,088 & 0,090 & $0,104^{*}$ & 0,029 \\
\hline B1 & Gestão e Produção & 0,114 & $0,118^{\star}$ & 0,032 & 0,023 \\
\hline A2 & Brazilian Business Review & 0,000 & 0,000 & 0,000 & 0,000 \\
\hline A2 & Organizações \& Sociedade & 0,066 & $0,093^{*}$ & 0,000 & 0,000 \\
\hline A2 & Revista Brasileira de Gestão de Negócios & 0,000 & 0,000 & 0,000 & 0,000 \\
\hline \multirow[t]{2}{*}{ A2 } & Revista Brasileira de Pesquisa em Turismo & 0,000 & 0,000 & 0,000 & 0,000 \\
\hline & Média Scielo FI & 0,097 & $0,114^{*}$ & 0,109 & 0,108 \\
\hline
\end{tabular}

Fonte: Elaborado pelos autores.

Nota 1. *ano em que o periódico teve seu maior impacto; Nota 2. verde - indica aumento em relação ao ano anterior; vermelho: indica queda em relação ao ano anterior. 
Nas bases Google Scholar e Spell, analisamos a medida h5-index e as medidas h-Spell, Spell 2 anos e Spell 5 anos do ano de 2016. Considerando os periódicos nacionais da área que estão indexados nessas bases, temos respectivamente 129 periódicos entre os estratos A2 e B4 e 98 periódicos entre os estratos A2 e B3, quantidade consideravelmente superior quando comparada às bases da Web of Science, Scopus e Scielo. Na Tabela 5 são descritas as quantidades, médias, os desvios padrões e os valores de distribuição empírica das variações dos dados para as medidas calculadas por cada base. A análise descritiva demonstra que quanto maior os estratos do Qualis, maior a média de impacto dos periódicos, porém, os desvios padrões também são maiores, ou seja, em estratos mais elevados, ao comparar os valores de impacto entre os diferentes periódicos, periódicos que possuem conceito Qualis inferior a outros periódicos podem possuir valores de impacto maiores que os periódicos de estratos superiores, e viceversa. Na medida h5-index a média variou de 12,04 (estrato A2) a 3,9 (estrato B4), no h-Spell o impacto foi de 11,7 (estrato A2) a 2,4 (estrato B3), no Spell 2 anos de 0,354 (estrato A2) a 0,075 (estrato B3), e no Spell 5 anos de 0,555 (estrato A2) a 0,091 (estrato B3), conforme Tabela 5:

Tabela 5. Dados Descritivos das Medidas de Impacto

\begin{tabular}{cccccccccc}
\hline Índice & Qualis & N & Média & DesvPad & Mínimo & Q1 & Mediana & Q3 & Max \\
\hline h5-index & A2 & 16 & 12,4 & 4,5 & 7,0 & 8,3 & 11,5 & 16,8 & 22,0 \\
& B1 & 26 & 7,8 & 2,7 & 4,0 & 6,0 & 7,0 & 10,0 & 16,0 \\
& B2 & 37 & 6,2 & 1,9 & 3,0 & 5,0 & 6,0 & 7,0 & 13,0 \\
& B3 & 30 & 4,3 & 1,8 & 1,0 & 3,0 & 4,0 & 5,3 & 8,0 \\
& B4 & 20 & 3,9 & 1,7 & 1,0 & 2,3 & 4,0 & 5,8 & 6,0 \\
\hline h-Spell* & A2 & 16 & 11,7 & 6,8 & 4,0 & 7,0 & 9,0 & 16,8 & 28,0 \\
& B1 & 22 & 6,1 & 2,0 & 3,0 & 5,0 & 6,0 & 7,3 & 11,0 \\
& B2 & 37 & 3,9 & 1,5 & 1,0 & 3,0 & 4,0 & 5,0 & 9,0 \\
& B3 & 23 & 2,4 & 1,5 & 1,0 & 1,0 & 2,0 & 3,0 & 7,0 \\
\hline Spell & A2 & 15 & 0,354 & 0,208 & 0,111 & 0,219 & 0,263 & 0,505 & 0,880 \\
2 anos & B1 & 21 & 0,196 & 0,096 & 0,069 & 0,103 & 0,200 & 0,283 & 0,376 \\
& B2 & 29 & 0,132 & 0,054 & 0,000 & 0,095 & 0,134 & 0,178 & 0,254 \\
& B3 & 16 & 0,075 & 0,046 & 0,000 & 0,043 & 0,082 & 0,108 & 0,145 \\
\hline Spell & A2 & 15 & 0,555 & 0,261 & 0,156 & 0,443 & 0,480 & 0,608 & 1,194 \\
5 anos & B1 & 21 & 0,276 & 0,126 & 0,085 & 0,178 & 0,250 & 0,359 & 0,525 \\
& B2 & 29 & 0,183 & 0,063 & 0,000 & 0,154 & 0,175 & 0,223 & 0,292 \\
& B3 & 16 & 0,091 & 0,040 & 0,038 & 0,062 & 0,076 & 0,121 & 0,168 \\
\hline
\end{tabular}

Fonte: Elaborado pelos autores.

Nota. A medida h-Spell contém número maior de dados válidos que o Spell 2 anos e Spell 5 anos.

Realizamos também o teste de correlação de Spearman da amostra de periódicos que estão indexados em ambas as bases. Para a correlação das quatro medidas mencionadas, o número de dados válidos foi de 64 periódicos. Seguindo os preceitos de Hair et al. (2009) identificamos a 
correlação entre alguns índices, tais como a correlação entre h5-index e h-Spell $(0,853)$ e entre Spell 2 anos e Spell 5 anos $(0,871)$.

Portanto, principalmente no que se refere às medidas h5-index e h-Spell, que são oriundas de diferentes bases, é possível constatar que ambas mensuram de forma semelhante o real impacto de periódicos, possibilitando realizar inferências fidedignas a respeito do impacto dos periódicos nacionais do campo de Administração, Contabilidade e Turismo. As correlações entre os outros indicadores demonstraram-se, em geral, de grau médio, sendo 0,571 entre h5-index e Spell 2 anos, 0,726 entre h5-index e Spell 5 anos, 0,613 entre h-Spell e Spell 2 anos e 0,783 entre h-Spell e Spell 5 anos. Na Figura 2 ilustramos, a partir do gráfico de correlação com linha de tendência, o panorama da amostra analisada para a correlação entre a medida h5-index do Google Scholar e h-Spell da base Spell, considerando o estrato Qualis de cada periódico (entre A2 e B3):

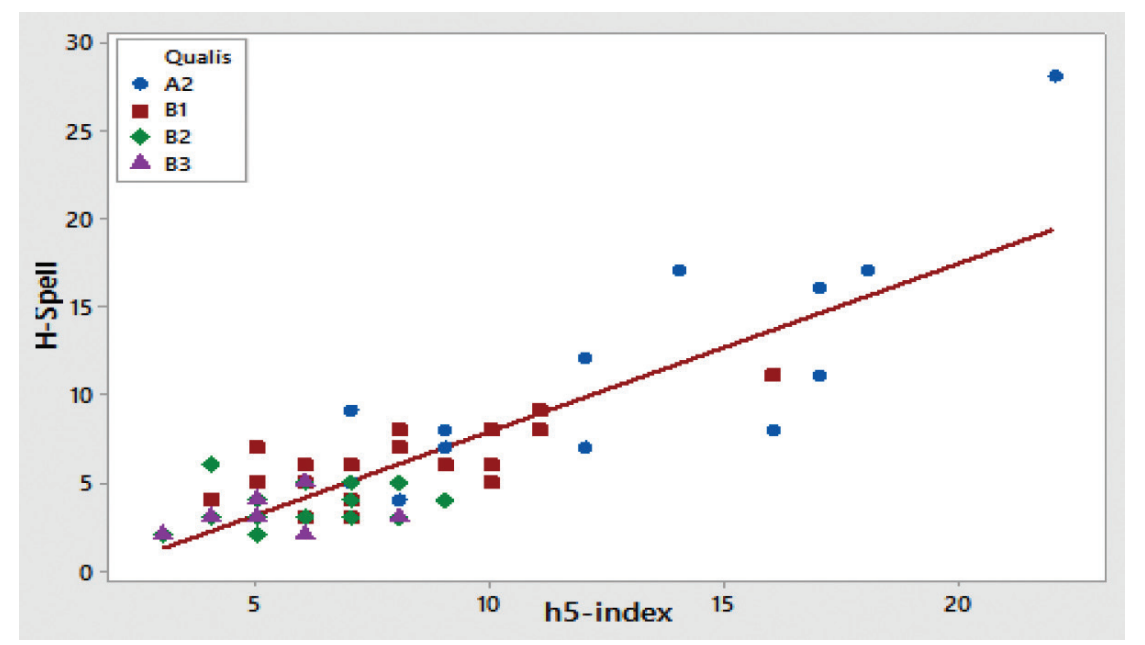

Figura 2. Correlação entre h5-index e h-Spell para Diferentes Estratos

Fonte: Elaborado pelos autores.

Em seguida, realizamos o teste de diferença entre grupos (ANOVA) para verificar se existe diferença estatisticamente significante na média do impacto dos periódicos entre as classificações do Qualis-Capes nos diferentes indicadores analisados (h5-index, h-Spell, Spell 2 e 5 anos). O teste ANOVA demostrou, com um intervalo de confiança de 95\%, a existência de diferença estatisticamente significante $(\mathrm{sig}=0,000)$. Em seguida, dado que há cinco grupos para a base Scholar (A2 a B4) e quatro para Spell (A2 a B3), aplicamos o Teste de Tukey na comparação dos grupos específicos (Tabela 6).

A análise de diferença de grupos demonstra que para o impacto h5index existe diferença estatisticamente significante $($ sig $=0,000)$ entre os estratos A2 e B1, A2 e B2, A2 e B3, A2 e B4, B1 e B3, B1 e B4, B2 e $\mathrm{B} 3$, e B2 e B4. Todavia, o teste demonstra que não há diferença entre as médias de impacto entre os estratos B2 e B1 e B3 e B4. A análise do h-Spell é bastante semelhante, porém neste caso não estão presentes periódicos do estrato B4. A análise do indicador evidencia que não existe diferença significante entre as médias dos estratos B3 e B2, e que embora a diferença entre B2 e B1 não seja estatisticamente significante, está muito próxima do 
limite para o teste $(\operatorname{sig}=0,051)$. Já os testes de diferença de médias de Spell 2 e 5 anos se assemelham, mostrando que entre B1 e B2 e B2 e B3 não há diferença entre as médias, sendo respectivamente 0,167 e 0,087 para a primeira medida e 0,343 e 0,132 para a segunda, conforme Tabela 6:

Tabela 6. Resultados do Teste de Tukey entre Diferentes Estratos

\begin{tabular}{|c|c|c|c|c|c|c|c|c|c|c|}
\hline \multicolumn{6}{|c|}{ Google Scholar (h5-index) } & \multicolumn{5}{|c|}{ Spell (h-Spell) } \\
\hline Qualis & $\begin{array}{c}\text { Dif. } \\
\text { Médias }\end{array}$ & $\begin{array}{l}\text { EP da } \\
\text { Dif. }\end{array}$ & IC (95\%) & Valor-T & $\begin{array}{c}\text { Valor-P } \\
\text { Ajust. }\end{array}$ & $\begin{array}{c}\text { Dif. } \\
\text { Médias }\end{array}$ & $\begin{array}{c}\text { EP da } \\
\text { Dif. }\end{array}$ & IC (95\%) & Valor-T & $\begin{array}{c}\text { Valor-P } \\
\text { Ajust. }\end{array}$ \\
\hline $\mathrm{B} 1-\mathrm{A} 2$ & $-4,529$ & 0,794 & $\begin{array}{l}(-6,729 \\
-2,328)\end{array}$ & $-5,7$ & 0,000 & $-5,600$ & 1,020 & $\begin{array}{l}(-8,26 \\
-2,93)\end{array}$ & $-5,5$ & 0,000 \\
\hline$B 2-A 2$ & $-6,132$ & 0,748 & $\begin{array}{l}(-8,204 \\
-4,060) \\
\end{array}$ & $-8,2$ & 0,000 & $-7,769$ & 0,927 & $\begin{array}{c}(-10,193 \\
-5,344)\end{array}$ & $-8,38$ & 0,000 \\
\hline $\mathrm{B} 3-\mathrm{A} 2$ & $-8,075$ & 0,773 & $\begin{array}{c}(-10,219 \\
-5,931)\end{array}$ & $-10,44$ & 0,000 & $-9,300$ & 1,010 & $\begin{array}{c}(-11,93 \\
-6,66)\end{array}$ & $-9,22$ & 0,000 \\
\hline $\mathrm{B} 4-\mathrm{A} 2$ & $-8,475$ & 0,838 & $\begin{array}{c}(-10,798 \\
-6,152)\end{array}$ & $-10,11$ & 0,000 & - & - & - & - & - \\
\hline $\mathrm{B} 2-\mathrm{B} 1$ & $-1,603$ & 0,639 & $\begin{array}{c}(-3,375 \\
0,169)\end{array}$ & $-2,51$ & 0,096 & $-2,172$ & 0,834 & $\begin{array}{c}(-4,353 \\
0,009)\end{array}$ & $-2,61$ & 0,051 \\
\hline $\mathrm{B} 3-\mathrm{B} 1$ & $-3,546$ & 0,669 & $\begin{array}{l}(-5,402 \\
-1,691)\end{array}$ & $-5,3$ & 0,000 & $-3,700$ & 0,924 & $\begin{array}{l}(-6,116 \\
-1,283)\end{array}$ & $-4,01$ & 0,001 \\
\hline $\mathrm{B} 4-\mathrm{B} 1$ & $-3,946$ & 0,743 & $\begin{array}{l}(-6,006 \\
-1,886)\end{array}$ & $-5,31$ & 0,000 & - & - & - & - & - \\
\hline B3 - B2 & $-1,943$ & 0,614 & $\begin{array}{l}(-3,645 \\
-0,242) \\
\end{array}$ & $-3,17$ & 0,016 & $-1,528$ & 0,822 & $\begin{array}{c}(-3,679 \\
0,624)\end{array}$ & $-1,86$ & 0,253 \\
\hline B4 - B2 & $-2,343$ & 0,693 & $\begin{array}{l}(-4,265 \\
-0,421) \\
\end{array}$ & $-3,38$ & 0,008 & - & - & - & - & - \\
\hline \multirow[t]{2}{*}{ B4 - B3 } & $-0,400$ & 0,721 & $\begin{array}{c}(-2,399 \\
1,599)\end{array}$ & $-0,55$ & 0,981 & - & - & - & - & - \\
\hline & \multicolumn{5}{|c|}{ Spell (Spell 2 anos) } & \multicolumn{5}{|c|}{ Spell (Spell 5 anos) } \\
\hline Qualis & $\begin{array}{c}\text { Dif. } \\
\text { Médias }\end{array}$ & $\begin{array}{c}\text { EP da } \\
\text { Dif. }\end{array}$ & IC (95\%) & Valor-T & $\begin{array}{c}\text { Valor-P } \\
\text { Ajust. }\end{array}$ & $\begin{array}{c}\text { Dif. } \\
\text { Médias }\end{array}$ & $\begin{array}{c}\text { EP da } \\
\text { Dif. }\end{array}$ & IC (95\%) & Valor-T & $\begin{array}{c}\text { Valor-P } \\
\text { Ajust. }\end{array}$ \\
\hline $\mathrm{B} 1-\mathrm{A} 2$ & $-0,158$ & 0,037 & $\begin{array}{c}(-0,2543 \\
-0,0619) \\
\end{array}$ & $-4,31$ & 0,000 & $-0,279$ & 0,046 & $\begin{array}{l}(-0,3990 \\
-0,1593) \\
\end{array}$ & $-6,11$ & 0,000 \\
\hline$B 2-A 2$ & $-0,223$ & 0,035 & $\begin{array}{l}(-0,3135 \\
-0,1324) \\
\end{array}$ & $-6,46$ & 0,000 & $-0,372$ & 0,043 & $\begin{array}{l}(-0,4845 \\
-0,2590) \\
\end{array}$ & $-8,65$ & 0,000 \\
\hline $\mathrm{B} 3-\mathrm{A} 2$ & $-0,280$ & 0,039 & $\begin{array}{l}(-0,3819 \\
-0,1773) \\
\end{array}$ & $-7,17$ & 0,000 & $-0,463$ & 0,049 & $\begin{array}{l}(-0,5908 \\
-0,3359) \\
\end{array}$ & $-9,54$ & 0,000 \\
\hline $\mathrm{B} 2-\mathrm{B} 1$ & $-0,065$ & 0,031 & $\begin{array}{c}(-0,1464 \\
0,0168)\end{array}$ & $-2,08$ & 0,167 & $-0,093$ & 0,039 & $\begin{array}{c}(-0,1942 ; \\
0,0090) \\
\end{array}$ & $-2,39$ & 0,087 \\
\hline B3 - B1 & $-0,122$ & 0,036 & $\begin{array}{l}(-0,2159 \\
-0,0270) \\
\end{array}$ & $-3,37$ & 0,006 & $-0,184$ & 0,045 & $\begin{array}{l}(-0,3018 \\
-0,0665) \\
\end{array}$ & $-4,11$ & 0,001 \\
\hline B3 - B2 & $-0,057$ & 0,034 & $\begin{array}{c}(-0,1453 \\
0,0320)\end{array}$ & $-1,68$ & 0,343 & $-0,092$ & 0,042 & $\begin{array}{c}(-0,2020 \\
0,0188)\end{array}$ & $-2,18$ & 0,139 \\
\hline
\end{tabular}

Fonte: Elaborado pelos autores. 
Na Tabela 7 sintetizamos os resultados do teste de diferença entre grupos a fim de ilustrarmos a existência ou não de diferença estatisticamente significante entre as médias de impacto nos diferentes estratos Qualis a partir das medidas de impacto consideradas. Nota-se que nos periódicos de estrato A2 existe diferença de impacto significativa ao compará-los com os outros conceitos Qualis nas variadas medidas de impacto analisadas. No caso dos periódicos de estrato B1, todas as medidas indicam que não existe diferença com o estrato B2, por outro lado, há diferença ao compararmos com os estratos B3 e B4. Já os resultados para os periódicos de estrato B2 é mais controverso, haja vista que para o indicador h5-index existe diferença entre as médias de B2 e B3, mas na análise de todas as medidas da base Spell o teste Tukey demostra que não há diferença significativa entre as médias, assim como também não há ao compararmos os estratos B3 e B4 na medida h5-index.

Tabela 7. Síntese dos Resultados do Teste de Tukey

\begin{tabular}{|c|c|c|c|c|}
\hline Teste ANOVA (Tukey) & h5-index & h-Spell & Spell 2 anos & Spell 5 anos \\
\hline Diferença entre o impacto de A2 e B1 & $\sqrt{ }$ & $\sqrt{ }$ & $\sqrt{ }$ & $\checkmark$ \\
\hline Diferença entre 0 impacto de A2 e B2 & $\checkmark$ & $\checkmark$ & $\checkmark$ & $\checkmark$ \\
\hline Diferença entre o impacto de A2 e B3 & $\checkmark$ & $\checkmark$ & $\checkmark$ & $\checkmark$ \\
\hline Diferença entre 0 impacto de A2 e B4 & $\sqrt{ }$ & _ & _ & _ \\
\hline Diferença entre o impacto de B1 e B2 & $x$ & $x$ & $x$ & $x$ \\
\hline Diferença entre 0 impacto de B1 e B3 & $\checkmark$ & $\checkmark$ & $\checkmark$ & $\checkmark$ \\
\hline Diferença entre o impacto de B1 e B4 & $\checkmark$ & - & - & - \\
\hline Diferença entre o impacto de B2 e B3 & $\sqrt{ }$ & $x$ & $x$ & $x$ \\
\hline Diferença entre 0 impacto de B2 e B4 & $\checkmark$ & - & - & - \\
\hline Diferença entre o impacto de B3 e B4 & $x$ & - & - & - \\
\hline
\end{tabular}

Fonte: Elaborado pelos autores.

Os resultados apresentados trazem implicações para os periódicos de Administração, Contabilidade e Turismo, para a Capes e para os pesquisadores deste campo, os quais serão discutidos na próxima seção.

- Implicações e Recomendações para a Área de Administração, Contabilidade e Turismo

Quanto aos periódicos nacionais indexados na Web of Science, Scopus e Scielo, observamos a baixa presença de seu conjunto nestas bases e o irrisório crescimento do impacto de grande parte dos periódicos analisados entre 2013 e 2016. Os dados analisados revelam a necessidade de esforços conjuntos entre os periódicos para que de fato se insiram nas bases científicas mais relevantes no contexto de nossa área. Diniz (2017, p. 364), por exemplo, afirma que "o processo de negociação para entrada nessas bases deve ser mais bem articulado entre os vários periódicos que já estão nesse caminho. A experiência de uns certamente pode contribuir para a entrada de outros. E todos ganham". 
Gestores e editores de periódicos de nossa área devem articular iniciativas de colaboração que aproximem as experiências bem-sucedidas de indexação junto aos diferentes atores do campo, tal como as editoras privadas, ANPAD e Capes (Kimura, Carneiro, Alperstedt, \& Neto, 2014) na busca pela transferência de conhecimentos do processo de inserção e manutenção dos periódicos nas bases. Consequentemente, a entrada de um conjunto maior de periódicos de nosso campo nessas bases permitiria um maior intercâmbio de citações entre esses periódicos, facilitando o processo de projeção do impacto e da relevância do conjunto de periódicos frente à comunidade internacional. Rossoni (2018a), ao relatar sobre o caso bem-sucedido de indexação dos periódicos nacionais da área na base Spell, demonstra que a inclusão destes em uma base comum viabilizou tanto a maior acessibilidade como também o crescimento de suas citações.

Farias (2017) aponta ainda que os periódicos de nosso campo devem estar atentos para a qualidade dos artigos publicados, para a busca de parceria com autores de origem estrangeira e para uma profissionalização editorial do periódico; todavia, muitos dos nossos periódicos são restringidos por fatores orçamentários, haja vista que em sua grande maioria adotam o modelo de acesso aberto e são dependentes de financiamento público (Farias, 2017). De acordo com Diniz (2017) nossos periódicos têm adotado três principais iniciativas para a internacionalização: a publicação dos artigos em inglês, a vinculação dos periódicos a editoras comerciais de fora do país e a realização de iniciativas de chamadas para trabalhos internacionais. Por outro lado, ao adotar um tom mais crítico sobre como alguns de nossos periódicos têm se posicionado frente ao contexto de inserção nessas bases, Alcadipani (2017) afirma que os periódicos nacionais têm realizado uma cópia mal feita do modelo de publicação global e, consequentemente, acabam expondo as fragilidades de nossa produção para o contexto mundial, tornando as publicações em periódicos brasileiros marginais no conjunto de debates e relações de citações com a academia mundial.

Os achados do presente estudo também corroboram com Alcadipani (2017, p. 409): "Percebemos, ainda, que os periódicos nacionais em inglês são raramente citados por autores de fora do Brasil." Entendemos que os periódicos indexados nas bases que realizam cálculos de medida de impacto precisam fugir, principalmente, de duas fragilidades: (i) a dependência das autocitações para a formação de suas medidas de impacto e (ii) de citações apenas com origem no próprio país, ou seja, oriundas de outros periódicos brasileiros. Os resultados demonstram ainda que mesmo quando não há autocitação ou quando a citação não é decorrente de periódicos nacionais, estas acabam por ser oriundas de autores brasileiros que publicaram em periódicos estrangeiros. Como exemplo temos o caso da Revista de Administração de Empresas (RAE), que possui 65 citações de periódicos indexados na WoS: 46,1\% destas citações são do tipo autocitação e 36,9\% são oriundas de outros periódicos brasileiros, totalizando 83,1\% das citações da revista. Das 16,9\% de citações restantes, ou seja, 11 citações, vemos uma série de autores brasileiros que publicaram em periódicos estrangeiros e citaram o próprio periódico, como Brito, Brito e Hashiba (2014) no Journal of Business Research, Joia e Lemos (2009) no Journal of Knowledge Management, Serra, Três e Ferreira (2016), no European Management Review, Pozzebon, Cunha e Coelho (2016) no periódico Information and Organization, entre outros. 
Entendemos, por conseguinte, que é preciso que os periódicos busquem alternativas para alavancar seus impactos a partir de autores de origem estrangeira que os citem, para de fato falarmos em uma maior internacionalização de nossa pesquisa em um contexto global. Como exemplo, tem-se a iniciativa recente da Revista de Administração de Empresas (RAE), no ano de 2017, que ao publicar a edição especial sobre Dynamic Capabilities, trouxe diversos artigos publicados em inglês e de autores consagrados, como David Teece, Roy Suddaby e Martha Feldman (Takahashi, Bulgacov, Bitencourt, \& Kaynak, 2017). A atração de autores estrangeiros consagrados possibilita que o periódico seja compreendido enquanto meio científico legítimo frente à comunidade internacional.

Do contrário, se nossos periódicos não conseguem atrair significativamente autores de origem estrangeira - quanto às citações e não conseguem ser citados por periódicos internacionais, não há que se falar em uma real internacionalização dos periódicos e da academia brasileira na comunidade internacional. Sales, Mello e Sandes-Guimarães (2017, p. 515) afirmam que "naturalmente, a indexação nessas bases de dados leva à internacionalização, que certamente é benéfica para visibilidade das nossas pesquisas, atração de artigos de pesquisadores internacionais, assim como parcerias." Temos um ponto de discordância quanto a esta afirmação, uma vez que a simples indexação nas bases não leva a uma internacionalização, pelas razões já expostas. É necessário ressaltar também o fato de os dados demonstrarem um irrisório crescimento do impacto de nossos principais periódicos nas bases Scopus e Scielo, com crescimento médio de impacto acumulado de apenas 0,066 e 0,107 respectivamente, no quadriênio 2013-2016 (vide Tabela 4). Por outro lado, Rossoni (2018b), ao defender a necessidade de que as publicações de nossos periódicos sejam mantidas em português, alerta para o fato de que a estratégia de internacionalização dos periódicos poderia levar a uma não internacionalização da produção, tendo em vista que ao incorporar o inglês como idioma central, e cada vez mais a atração de autores e corpo editorial estrangeiro, a produção do conhecimento local ficaria em segundo plano ou até mesmo inexistente.

As análises realizadas dos periódicos nacionais indexados nas bases Google Scholar e Spell trazem implicações relevantes sobre a utilização das medidas dessas bases para a avaliação da qualidade de nossos periódicos, sendo atribuída atualmente principalmente à Capes. Dentro deste aspecto, Rossoni e Guarido Filho (2012) ao analisarem os periódicos científicos da área de Administração, atentam para o fato das limitações existentes no modelo cerimonialista de atividade científica que é instituído em nosso campo, e evidenciam empiricamente que a qualidade do conjunto de periódicos é determinada em grande medida pelo sistema de relações subjetivas e de prestígio instituídas entre pesquisadores do campo. Sob essa lógica, mesmo com a adoção de medidas mais objetivas para a classificação de periódicos nas avaliações mais recentes do último Quadriênio (Capes, 2017), observamos que esse modelo ainda está presente ao verificarmos que determinados periódicos são selecionados para estratos maiores de classificação sem atingirem o critério estabelecido no Qualis da área. Além disso, verificamos que atualmente especialistas definem medidas 
e critérios de impacto e desconsideram, em alguns casos, um variado número de possibilidades de medidas existentes, conforme demonstramos no decorrer deste artigo.

Nossa análise, em certa medida, buscou desvelar tais limitações ao trazer para discussão, para além de um critério objetivo único, um rol de possibilidades a partir das diferentes medidas de impacto existentes, haja vista que mesmo que a utilização de uma determinada medida objetiva de impacto diminua assimetrias e vieses de julgamento (Rossoni, 2018a), a mesma também pode limitar e criar novas assimetrias na avaliação de qualidade dos periódicos devido à natureza de suas fontes e fórmulas ou pelo uso e delimitações realizadas pelo grupo cerimonial que tem o poder de definir e determinar os critérios e limites para os periódicos de nosso campo.

Entendemos, portanto, que a avaliação de nossos periódicos pode considerar para o futuro medidas de impacto que ainda não são levadas em consideração para a classificação dos periódicos no Qualis-periódicos. Nossos resultados mostraram, por exemplo, que os índices h5-index (Google Scholar) e h-Spell (Spell) possuem alta correlação $(0,853)$, o que demonstra a confiabilidade de ambas as bases e medidas para a realização de inferências confiáveis a respeito do impacto dos periódicos de nosso campo. No entanto, entre essas duas somente uma das medidas da base Spell é utilizada para a avaliação dos periódicos. Considerando o maior número de periódicos de nossa área indexados na base Google Scholar, a maior abrangência desta base quanto ao número de periódicos e outras fontes de citação indexados, sua facilidade de uso global e a alta correlação com uma base já utilizada, porém de âmbito estritamente nacional (Spell), compreendemos que sua adoção pode ser importante para a avaliação de nossa publicação acadêmica. Sua adoção seria, portanto, oportuna.

Adicionalmente, entendemos que o uso de mais indicadores de impacto evitaria a ocorrência de erros de análise quanto ao real impacto das revistas e, consequentemente, erros na classificação do Qualis-periódicos em seus diferentes estratos. Ora, apesar de haver alta correlação entre h5-index e h-Spell, há casos de revistas que estão melhor posicionadas na primeira base, como é o caso de RAM (h5-index = 16), RAl (h5-index =11) e Revista da UFSM (h5-index =11). Ao analisarmos esse indicador observamos que essas revistas possuem maior impacto que periódicos classificados em estratos maiores, o que sugere que o uso destes indicadores de impacto pode ser útil para os critérios de classificação adotados pela Capes e benéfico para a representação objetiva dos reais impactos de nossos periódicos.

Além disso, o teste estatístico de diferença entre as médias indicou que o atual sistema de classificação estabelecido pela Capes não consegue distinguir adequadamente as diferenças de impacto, principalmente entre os estratos B1 e B2, B2 e B3, e B3 e B4, permitindo a perpetuação do "efeito Matheus" (Rossoni, 2018a), em que há distorções do real impacto dos periódicos causadas pelo sistema cerimonial de delimitação dos critérios atualmente estabelecidos. Nos periódicos classificados como A2, embora os resultados demostrem a existência de diferença significativa entre este estrato e as outras classificações, observamos incoerências em relação a alguns periódicos que possuem valores de impacto elevados, mas que se encontram em níveis inferiores de classificação no Qualis-periódicos se comparados a outras revistas e vice-versa (ver Tabela 4). 
Além das implicações para os periódicos e para a Capes, entendemos que os esforços de nosso estudo evidenciam para os pesquisadores, sejam eles alunos de Mestrado e Doutorado ou membros do Corpo Docente de programas de Stricto Sensu, que o sentido do que determina o impacto de uma revista é mais amplo do que o evidenciado pelo critério Qualis-periódicos, apesar de sua inegável importância. O pesquisador tem a possibilidade, portanto, de levar em consideração as diversas medidas para a escolha de suas publicações, observando não somente o critério da Capes, mas também as possíveis tendências e relações em termos dos diferentes impactos - como o histórico de crescimento dos periódicos nos últimos anos e os indexadores de que os periódicos fazem parte. Essas análises amenizam, por exemplo, incertezas em relação aos periódicos que não serão bem avaliados em próximos períodos. Os dados trazidos neste artigo fornecem, portanto, subsídios para as escolhas dos pesquisadores quanto às publicações de seus estudos, sob diferentes óticas de seus impactos e, por esta razão, podem ser considerados subsídios estratégicos para suas carreiras.

\section{Considerações Finais: A Presença, o Impacto e a Internacionalização de Periódicos}

Ao atingir o objetivo de analisar a classificação dos periódicos brasileiros de Administração, Contabilidade e Turismo nas diferentes bases científicas que calculam fator de impacto, nosso estudo traz duas contribuições centrais para o campo: a primeira relacionada a nossa análise de periódicos e a segunda referente às medidas das bases científicas.

Observamos, com base nos dados coletados, que os periódicos nacionais da área têm tido ínfimo crescimento nos índices calculados pelas bases Scopus e Scielo, o que indica que nossas revistas não têm conseguido aumentar razoavelmente o impacto internacional de suas publicações. Defendemos, portanto, que a simples presença nas bases não garante disseminação internacional das revistas. Também notamos que ainda temos poucos periódicos nacionais presentes na principal base internacional que calcula fator de impacto, a Web of Science - são apenas três periódicos de uma população de 304 no campo, ou seja, cerca de 1\% da população. De forma conjunta esses três periódicos têm tido um crescimento razoável em seus fatores de impacto na Web of Science, entretanto, evidenciamos que este aumento tem sido decorrente substancialmente de autocitações, de citações oriundas de outros periódicos nacionais e de autores brasileiros que publicam em periódicos estrangeiros, o que nos levou a trazer reflexões sobre a real internacionalização de nosso campo.

Sobre as bases Google Scholar e Spell, nossos testes estatísticos indicaram uma alta correlação entre as medidas h5-index e h-Spell, e Spell 2 e 5 anos, e também a inexistência de diferença entre as médias de impacto entre alguns estratos Qualis nos indicadores h5-index, h-Spell, e Spell 2 e 5 anos sem autocitação, o que nos levou a refletir e recomendar a inclusão de novas bases científicas para a classificação de nossos periódicos e a consideração de uma gama maior de medidas de impacto 
a serem consideradas nos critérios de avaliação pelo Qualis-Periódicos. Outro resultado encontrado foi a alta variação no impacto de um mesmo periódico em diferentes bases, o que também nos levou a defender essa necessidade de inclusão de novas medidas de impacto para a classificação, pois atualmente há periódicos nacionais que são considerados como de médio impacto em determinadas bases e que não fazem parte do critério Capes (apesar de serem fidedignas), e de baixo impacto em bases que são utilizadas pela Capes. Nossa reflexão central é a de que a classificação se torna mais frágil ao não levar em conta essas referências que têm sido globalmente utilizadas pela comunidade acadêmica.

Com base nas inquietudes surgidas no decorrer de nosso estudo, indicamos uma série de questões endereçadas aos futuros estudos sobre o tema, quais sejam: Qual é o perfil de citações de journals internacionais presentes nas principais bases científicas quando comparado aos periódicos brasileiros do campo? Quais estratégias de gestão editorial estes periódicos têm adotado para alavancar suas citações e para aumentar sua disseminação internacional? Quais são os critérios utilizados por outros países para avaliarem seus periódicos nacionais e de que forma este benchmarking pode ajudar na proposição de métodos de classificação de periódicos que beneficiem a academia brasileira? Entendemos que nosso estudo atingiu a finalidade proposta e que novos esforços de pesquisa serão fundamentais para fomentar um debate que consideramos ainda incipiente no Brasil: o da inserção e impacto global de nossos periódicos e produção científica.

\section{Referências}

Aguado-López, E., Garduño-Oropeza, G.A, Rogel-Salazar, R., \& Zúñiga-Roca, M.F (2012). The need and viability of a mediation index in Latin American scientific production and publication: The case of the Redalyc System of Scientific Information. Aslib Proceedings, 64(1), 8-31.

Alcadipani, R. (2017). Periódicos brasileiros em inglês: a mimica do publish or perish" global”. Revista de Administração de Empresas, 57(4), 405-411.

Anderson, D. R., Sweeney, D. J., \& Williams, T. A. (2007). Estatística aplicada à administração e economia. São Paulo: Thomson Learning.

Blattmann, U., \& Santos, R. N. M. (2014). Revistas científicas brasileiras e sua visibilidade no acesso aberto. Informação \& Sociedade, 24(3), 99-106.

Brito, L. A. L., Brito, E. P. Z., \& Hashiba, L. H. (2014). What type of cooperation with suppliers and customers leads to superior performance? Journal of Business Research, 67(5), 952-959.

Burrell, G., \& Morgan, G. (1979). Sociological paradigms and organizational analysis. London, England: Heinemann.

Collazo-Reyes, F. (2014). Growth of the number of indexed journals of Latin America and the Caribbean: the effect on the impact of each country. Scientometrics, 98(1), 197-209.

Cunliffe, A. L. (2011). Crafting qualitative research: Morgan and Smircich 30 years on. Organizational Research Methods, 14(4), 647-673. 
Capes (2017). Relatório do processo de classificação de periódicos Área de Administração, Ciências Contábeis e Turismo Quadriênio 2013-2016. Recuperado em 15 março, 2017, de: https://www.capes.gov.br/images/stories/download/ avaliacaotrienal/Docs_de_area/qualis/administracao_ciencias_contabeis_e_ turismo.pdf.

Creswell, J (2007). W. Research design: Qualitative, quantitative, and mixed methods approaches. Thousand Oaks: Sage publications.

Diniz, E. H. (2017). Periódicos brasileiros da área de Administração no contexto de internacionalização da produção científica. Revista de Administração de Empresas, 57(4), 357-364.

Falagas, M. E., Pitsouni, E. I., Malietzis, G. A., \& Pappas, G. (2008). Comparison of PubMed, Scopus, web of science, and Google scholar: strengths and weaknesses. The FASEB Journal, 22(2), 338-342.

Farias, S. A (2017). Internacionalização dos periódicos brasileiros. Revista de Administração de Empresas, 57(4), 401-404.

Ferreira, M. P. (2015). Periódicos e rankings de periódicos em administração. Revista Pensamento Contemporâneo em Administração, 9(2), 1-16.

Hair, J. F., Black, W. C., Babin, B. J., Anderson, R. E., \& Tatham, R. L. (2009). Análise multivariada de dados. Porto Alegre: Bookman.

Harzing, A. W., \& Alakangas, S. (2016). Google Scholar, Scopus and the Web of Science: a longitudinal and cross-disciplinary comparison. Scientometrics, 106(2), 787-804.

Joia, L. A., \& Lemos, B. (2010). Relevant factors for tacit knowledge transfer within organisations. Journal of Knowledge Management, 14(3), 410-427.

Kimura, H., Carneiro, J., Alperstedt, G. D., \& Neto, A. C. (2014). O processo de internacionalização de periódicos nacionais. Revista de Administração Contemporânea, 18(6), 1-3.

Machado-da-Silva, C. L., Guarido Filho, E. R., Rossoni, L., \& Graeff, J. F. (2008). Periódicos brasileiros de Administração: Análise bibliométrica de impacto no triênio 2005-2007. Rac-Eletrônica, 2(3), 351-373.

Mingers, J., O'Hanley, J. R., \& Okunola, M. (2017). Using Google Scholar institutional level data to evaluate the quality of university research. Scientometrics, 113(3), 1627-1643.

Moed, H. F., Bar-llan, J., \& Halevi, G. (2016). A new methodology for comparing Google Scholar and Scopus. Journal of Informetrics, 10(2), 533-551.

Mongeon, P., \& Paul-Hus, A. (2016). The journal coverage of Web of Science and Scopus: a comparative analysis. Scientometrics, 106(1), 213-228.

Morgan, G., \& Smircich, L. (1980). The Case for Qualitative Research. Academy of Management Review, 5(4), 491-500.

Mugenda, O. M. (1999). Research methods: Quantitative and qualitative approaches. Nairobi: African Centre for Technology Studies.

Neuman, L. W. (2014). Social research methods. Londres: Pearson Education Limited. 
Oliveira, C. C. V., Cendón, B. V., \& Cirino, S. D. (2017). Aspectos estruturais considerados nos estudos de qualidade dos periódicos científicos. Pesquisa Brasileira em Ciência da Informação e Biblioteconomia, 12(1), 94-106.

Pozzebon, M., Cunha, M. A., \& Coelho, T. R. (2016). Making sense to decreasing citizen e Participation through a social representation lens. Information and Organization, 26(3), 84-99.

Rosa, R. A., \& Romani-Dias, M. (2017, novembro). Periódicos científicos brasileiros a partir de seus indexadores: cenário atual e perspectivas futuras para a administração, contabilidade e turismo. Anais do ABECMEETING, Curitiba, PR, Brasil, 1. Recuperado em 10 dezembro, 2017, de: http://ocs.abecbrasil.org.br/index.php/abec-meeting/ abec-meeting-2017/paper/view/147

Rossoni, L. (2018a). O Spell reduziu o efeito Mateus na citação de periódicos. Revista Eletrônica de Ciência Administrativa, 17(1), I-VIII.

Rossoni, L. (2018b). Em Defesa das Publicações em Português. Revista Eletrônica de Ciência Administrativa, 17(3), I-XIII.

Rossoni, L., \& Guarido Filho, E. R. (2012). Onipresença nos conselhos editoriais: prestígio e cerimonialismo na atividade científica. Redes. Revista hispana para el análisis de redes sociales, 22(8), 189-218.

Sci\&Org - Ciência e Organizações. (2017). Qualis-Periódicos definitivo: Quadriênio (2013-2016) - Administração, Contabilidade e Turismo. Tendências Futuras para os Periódicos Científicos Brasileiros da Área. Recuperado em 16 abril, 2017, de: https:// sciandorg.wordpress.com/2017/10/23/qualis-periodicos-definitivo-quadrienio2013-2016-administracao-contabilidade-e-turismo-tendencias-futuras-para-osperiodicos-cientificos-brasileiros-da-area/

Saes, M. S. M., Mello, A., \& Sandes-Guimarães, L. V. D. (2017). Revistas brasileiras em Administração: Relevância para quem? Revista de Administração de Empresas, 57(5), 515-519.

Serra, F. R., Três, G., \& Ferreira, M. P. (2016). The 'CEO’ Effect on the Performance of Brazilian Companies: An Empirical Study Using Measurable Characteristics. European Management Review, 13(3), 193-205.

Simioni, L. C., Dallacorte, C., \& Jacoski, A. C. (2016). Proposição de um índice-h para a produção científica da construção civil nacional. Encontros Bibli: Revista Eletrônica de Biblioteconomia e Ciência da Informação, 21(46), 137-153.

Solomon, D. J. (2014). Digital distribution of academic journals and its impact on scholarly communication: Looking back after 20 years. The Journal of Academic Librarianship, 39(1), 23-28.

Takahashi, A. R. W., Bulgacov, S., Bitencourt, C. C., \& Kaynak, H. (2017). Expanding the dynamic capabilities view: special contributions. Revista de Administração de Empresas, 57(3), 209-214.

Trzesniak, P. (2016). Qualis in four quarters: history and suggestions for the Administration, Accounting and Tourism area. Revista Contabilidade \& Finanças, 27(72), 279-290.

Wood Jr, T., \& Costa, C. C. M. (2015). Avaliação do impacto da produção científica de programas selecionados de pós-graduação em Administração por meio do índice H. Revista de Administração (RAUSP), 50(3), 325-337. 